AL-QANȚARA

XXIX 2, julio-diciembre de 2008

pp. 293-305

ISSN 0211-3589

\title{
EL CALIFATO NAZARÍ
}

\section{THE NAṢRID CALIPHATE}

\author{
M. ${ }^{a}$ Jesús Rubiera MATA \\ Universidad de Alicante
}

Los soberanos de la dinastía Nasrí de Granada se intitulan sultanes o Amīr al-Musliminn en su abundante correspondencia exterior con otros príncipes musulmanes o cristianos. Sin embargo, a partir de la segunda dinastía, comienzan a utilizar también el título califal aunque parece que de forma privada, dentro del entorno familiar o el cortesano, tal como prueban determinados documentos (cartas privadas, lápidas, inscripciones palaciegas o poemas) emanados del Dìwān al-Inšà' nașrí. El califato ostentado por los Nașríes no es el mismo que el de los Omeyas o los Almohades que llevaba emparejado el título de Amìr al-Mu'minin y Jalīfat Rasūl Allāh, sino que lo acompañan del título de Jalīfat al-Rahmmān o Jalïfat Allāh, como otros soberanos musulmanes de la baja Edad Media. Su legitimidad está basada en una genealogía que les hace entroncar con los Jazrāŷ, es decir con los Anșār de Sa'd b. 'Ubāda, que pretendió proclamarse Califa a la muerte de Muhammad.

Palabras clave: Califato Nazarí; califa; sultán; Amìr al-Muslimīn; Amìr al-Mu'minin, Jalīfat Rasūl Allāh; Jalīfat al-Raḥmān; Jalīfat Allāh; Dīwān al-Inšā'.
The kings of the Nașrid dynasty of Granada employed the titles of sultan and Amīr al-Muslimin in their correspondence with other Muslim and Christian sovereigns. However, from the second dynasty onwards they start to use the title of Khalif $a$ as well although only in private circles such as the family and the court, as is demonstrated by documents emanating from the Nașrid Dīwān al-Inshā', personal letters, gravestones, palace inscriptions and poems. The caliphate proclaimed by the Nasrids is not the same as that of the Umayyads or the Almohads who assumed the dual title of Amīr al-Mu'minin and Khaliffat Rasūl Allāh, they added to it the title of Khalīfat al-Rậmān and Khalīfat Allāh as did other Muslim rulers in the Late Middle Ages. Their legitimacy is based on a genealogy starting with the Khazrāj, that is, from the ansār of Sa'd b. 'Ubāda who tried to proclaim himself caliph at the death of Muhammad.

Key words: Nașrid Caliphate; Khalīfa; Sultan; Amìr al-Muslimīn; Amīr al-Mu'minin; Khalīfat Rasūl Allāh; Khalīfat al-Raḥmān; Khalīfat Allāh; Dīwān al-Inshā'.

\section{Títulos califales de los Nazaríes}

La hipótesis planteada en estas páginas de que los sultanes Nazaríes adoptaron el título de califa, arranca de un poema epigráfico de Ibn Zamrak, el del Mirador de Lindaraja, donde se menciona el «trono del califato» (kursī l-jiläfa) ${ }^{1}$, tema que formó parte de una agria

${ }^{1}$ Se conserva in situ. Es el verso n. ${ }^{\circ} 7$ del Dīwān de Ibn Zamrak, Muhammad Tawfīq al-Nayfar (ed.), Beirut, 1997, 126. 
polémica, hoy superada ${ }^{2}$, en la que se debatía, entre otras cosas, dónde se encontraba el Salón del trono de Muhammad V sin dar importancia al hecho de que se hablaba de califato en lugar de reino como, en cambio, se dice en la Alcoba central del Palacio de Comares (kursī l-mulk) ${ }^{3}$. La adopción del título de Califa fue obra de la segunda dinastía Nazarí que, como otros soberanos musulmanes, a partir del siglo XIII no acompañan al título califal con la denominación de Amīr al-Mu'minin. Los sultanes Otomanos ${ }^{4}$ son el más ilustre ejemplo de ello; ni ellos ni los Nazaríes adoptan el título de Jalīfat Rasūl Allāh sino el de Jalïfat al-Raḥmān o Jalïfat Allāh, basándose en las aleyas coránicas siguientes:

«Él es el que os ha puesto como sucesores sobre la tierra» (Q, 6:165).

«Pondré un sucesor en la tierra» $(\mathrm{Q}, 2: 30)$.

Ibn Jaldūn no admite estas aleyas como justificación de «Califa de Allāh», puesto que la sucesión o vicaría sólo se puede emplear cuando hay alguien ausente y Allāh no lo está, ya que siempre está presente ${ }^{5}$. Por ello los Nazaríes buscaron, como veremos, otra justificación añadida para utilizar el título de Califa.

El título califal aplicado a los sultanes Nazaríes aparece con la frecuencia suficiente en diversas fuentes como para que podamos rastrear el proceso de su adopción. Estas fuentes son las emanadas del Dìwān al-Inšă ' nazarí, ya sean cartas, poemas o lápidas. El hecho de que utilicen a lo largo del tiempo diferentes fórmulas para hablar de los soberanos, llamando a unos sultanes y a otros califas, aun siendo obra de un mismo arráez del Diwwān al-Inšă', resalta su valor como fuente significativa.

La referencia del poema epigráfico al califato de Muhammad V no es única en el Dīwān de Ibn Zamrak, puesto que en la mayor parte de los panegíricos Muhammad V aparece mencionado como Califa. Podríamos pensar que es una hipérbole más de un poeta proclive a la exageración, pero es muy significativo que Yūsuf III, en tanto que recopilador del Dīwān de Ibn Zamrak ${ }^{6}$, mencione en su Prólogo que su

2 García Gómez, E., Foco de antigua luz sobre la Alhambra, Madrid, 1988.

3 Idem, Poemas árabes en los muros y fuentes de la Alhambra, Madrid, 1985, 107.

${ }^{4}$ Sourdel, D., "Khalifa", $E I^{2}$, Leiden-Paris, 1978, IV, 978.

5 Ibn Jaldūn, Muqaddima, ed. Beirut, s.a., libro III, cap. XXV, 135-136.

${ }^{6}$ Rubiera Mata, M. . J., "Ibn Zamrak, su biógrafo Ibn al-Aḥmar y los poemas epigráficos de la Alhambra", Al-Andalus, 43 (1977), 447-451. 
abuelo Muhammad V, satisfecho de cómo ejercía la kitāba, le confirió diversas funciones de su risāla y de su hiŷāba, es decir, que Ibn Zamrak, además de ser arráez del Diwwān al-Inšă ' - la kitāba -, desempeñó funciones de embajador - la risāla - y de hậŷib, cuando lo habitual es que se hablase de sus funciones de wazir. El texto del prólogo se encuentra en al-Maqqarī ${ }^{7}$ y el editor del Dìwān, M. Tawfīq al-Nayfar, no lo ha reeditado pero sí lo ha utilizado, y en nota a pie de página comenta que entre los Nazaríes no había huyyya $\bar{a} b$ sino visires ${ }^{8}$ porque, evidentemente, el título de hââyib sólo había sido utilizado en al-Andalus durante el Califato. Cabe preguntarse si Yūsuf III, nieto de $\mathrm{Mu}-$ hammad V, iba a cometer un error de esta naturaleza dado que además, y como mencionaremos más adelante, sí hubo un ḥâyi ib anterior a Ibn Zamrak, precisamente cuando empieza el «califato» de los Nazaríes, y que Yūsuf III también ostentaría el título de califa y tendría igualmente un hââyib: su ministro Abū 1-Surūr Mufarriŷy ${ }^{9}$.

En efecto, el poeta panegirista de Yūsuf III, Ibn Furkūn, le llama directamente califa ${ }^{10} \mathrm{y}$ en el epitafio de su lápida, que no se conserva en su totalidad pero cuyo texto fue copiado por Alonso del Castillo y reproducido por Emilio Lafuente Alcántara ${ }^{11}$, nos muestra una serie de circunloquios para hablar del califato. No se llama a Yūsuf III directamente califa sino que se dice al-mutahallà bi l-anāti wa l-hilmi fi-julafä' l-isläm, traducido por Lafuente como «el adornado con la semblanza y la mansedumbre entre los califas del Islam». Se menciona su laqab califal: al-Nāṣir li-dīn Allāh, nada menos que el mismo de 'Abd al-Raḥmān III. Su padre, Yūsuf II, es mencionado en la lápida como akramu l-jalā'if, es decir «el más generoso de los califas»; su laqab es al-Mustagnī bi-llāh. Muhammad V y Yūsuf I, abuelo y bisabuelo de Yūsuf, no son denominados califas, pero se mencionan sus laqab-s: al-Ganī bi-llāh y Mu'ayyad bi-llāh respectivamente, lo que parece mostrar que, como veremos, Yūsuf I también ostentó el título de Califa. Finalmente al primer emir de la segunda dinastía, Ismā'īl I, se le llama munŷib al-julafä', epónimo de los califas, porque el título

7 Azhār al-Riyāẹ, Cairo, 1949/1367, II, 12.

8 Ibn Zamrak, Dīwān, 13, nota 2.

9 Arié, R., L'Espagne musulmane au temps des Nasrides, Paris, 1973, 200.

${ }^{10}$ Ibn Furkūn, Dīwān, M. Bencherifa (ed.), Casablanca, 1987, 158, 190 y 193.

11 Lafuente Alcántara, E., Inscripciones árabes de Granada, Madrid, 1860, reed. facs., Granada, 2000, 232-236; Lévi-Provençal, E., Inscriptions arabes d'Espagne, Paris, 1931, 169-173. 
de califa lo adoptan los soberanos de la segunda dinastía. En efecto, es a Ismā'îl I al primero al que se le llama califa en el poema epigráfico del Generalife - exactamente Jalïfat al-Raḥmān- ${ }^{12}$. El carácter ambiguo, si no heterodoxo, de este título es posiblemente la razón de tantos circunloquios, a pesar de que ya en la época de Yùsuf III los Nazaríes habían encontrado una legitimidad para su califato, pero seguían utilizando este título de Jalïfat al-Raḥmān, por decirlo así, menos pretencioso que el de Jalïfat Rasül Alläh de los Omeyas y de los Abbasíes.

Al final de los tiempos Nazaríes una nueva lápida nos sigue hablando de su título califal y es el único lugar donde se utiliza Jalïfat Rasūl Allāh. Se trata del epitafio del príncipe Yūsuf Abū 1-Haŷŷâŷ (m. 871/1467), hermano de Muley Hacén, editado y traducido por Lafuente Alcántara ${ }^{13}$, Almagro Cárdenas ${ }^{14} \mathrm{y}$ Lévi-Provençal ${ }^{15}$. Se reproducen los laqab-s de Yūsuf II, Muhammad V y Yūsuf I con sus respectivos títulos de Jalïfat Rasūl Allāh. Ismā'īl I no tiene título ni laqab. El padre del príncipe, Sa'd (el rey Ciriza de los textos cristianos), también recibe el título de Jalïfat Rasūl Allāh y el laqab de al-Musta'īn bi-1lāh, que ya llevó otro califa nazarí, Muhammad VII, hijo de Yūsuf II y hermano de Yūsuf III. Sin embargo, en un documento de compraventa de la misma época ${ }^{16}$, al Emir Sa'd se le da el laqab de al-Musta'īn, se le llama Jalïfat Rabb al-'älamin y Amīr al-Muslimìn — es decir que no lleva título de Jalïfat Rasül Allāh-y lo que es más interesante, se dice que desciende de los califas Rašìūn.

\section{El Califato Nazarí y su legitimación}

El título de califa, según pensamos, fue ostentado por la segunda dinastía, puesto que no aparece en ningún texto referido a los Emires Muhammad II, Muhạmmad III y Nașr, ni en sus lápidas, ni en los panegíricos emanados del Dīwān al-Inšă

12 Lafuente Alcántara, Inscripciones, 190.

13 Ibidem, 237-240.

14 Almagro Cárdenas, A., "Inscripción sepulcral del príncipe Yusuf, hermano de Muley Hacén”, BRAH, 36 (1900), 348-356.

15 Lévi-Provençal, Inscriptions, 176-178.

16 Seco de Lucena, L., Documentos arábigo-granadinos, Madrid, 1961, 32-33.

Al-Qanțara (AQ) XXIX 2, julio-diciembre 2008, pp. 293-305 ISSN 0211-3589 
al-Ŷayyāb que, en cambio, sí llamará califa a Ismā‘īl I y a Yūsuf I ${ }^{17}$. En cuanto a Muhammad I, cabe mencionar que en su lápida es titulado Amìr al-Mu'minin; no aparece como califa ${ }^{18}$ debido seguramente a que el primer nazarí no debía de tener muy claro lo que exactamente era, puesto que este título, como hemos visto, no será utilizado por ninguno de sus descendientes aunque se llamen califas. Los títulos que sí aparecen en todos los emires de la primera dinastía son el de Imām, seguramente por herencia terminológica de los almohades ${ }^{19}, \mathrm{y}$ Anșār, título que todavía no implica una genealogía, como sucederá en la segunda dinastía, sino que en este caso se limita a exponer que Muhammad I era un auxiliar de la religión o del Profeta. Esta interpretación la merece cualquier soberano que defienda el Islam, según la sugerente teoría de Maribel Fierro ${ }^{20}$. Es indudable que, en sus genealogías, se menciona que descienden de Nașr, pero sin remontarse a Sa'd b. 'Ubāda y la tribu de Jazraŷ. Esta ascendencia encabeza la biografía de Muhammad I redactada por Ibn al-Jațīb, que fue escrita evidentemente cuando dicha ascendencia formaba parte ya de la doctrina oficial de la dinastía.

La primera vez que aparece el nombre de al-Jazraŷ como ancestro de los Nazaríes es en el epitafio de Nașr, muerto en el 722/1322 durante el Emirato de Ismā'îl I ${ }^{21} \mathrm{y}$, en cambio, no aparece en el de $\mathrm{Mu}-$ hammad III, su hermano, que tendría la misma ascendencia, pero que murió antes de que su epitafio pudiese ser redactado por el Dīwān al-Inš $\bar{a}^{\prime}$ de la segunda dinastía ${ }^{22}$. Los Nazaríes pretenden no ser unos simples anșäríes o auxiliares del Islam sino descender de los auténticos, los que ayudaron a Muhammad, lo que les permitiría arrogarse el título de califa. La razón es que Sa'd b. 'Ubāda había sido elegido califa por los Anșār, en una saqĩfa, a la muerte de Muhammad ${ }^{23} \mathrm{y}$ aun-

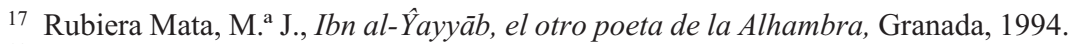

18 Ibn al-Jațīb, al-Lamha al-badriyya fi l-dawlati l-nașriyya, Beirut, 1980/1400, 48; idem, Ihātata, II, 100-101.

19 Fierro, M., "The Legal Policies of the Almohad Caliphs and Ibn Rushd's Bidāyat al-Mujtahid", Journal of Islamic Studies, 10, 3 (1999), 226-248.

${ }_{20}$ Idem, "The Anșārīs, Nāṣir al-dīn, and the Nașrids in al-Andalus", JSAI, 31 (2006), 232-247.

${ }^{21}$ Ibn al-Jatịib, al-Lamha, 77.

22 Ibn al-Ŷayyāb redactó los poemas de los epitafios nazaríes de los emires a los que sirvió como arráez del Dìwān al-inš $\bar{a}$ ' y es muy probable que redactase también el epitafio en prosa.

${ }^{23}$ Fierro, "The Anșārīs".

Al-Qanțara (AQ) XXIX 2, julio-diciembre 2008, pp. 293-305 ISSN 0211-3589 
que el intento no prosperó, Sa'd siguió considerándose jefe de la comunidad musulmana toda su vida. Esta genealogía permitía a los Nazaríes considerarse descendientes de los califas Rašídūn y en consecuencia más legítimos que los Omeyas.

Pensamos, por tanto, que el Califato Nazarí se inicia con Ismā'īl I, al que Ibn al-Ŷayāb en el Generalife llama Jalïfat al-Raḥmān y los epitafios de sus descendientes le señalan como tal. Ahora bien, el Califato Nazarí se asume como una cuestión privada, de puertas adentro, ya que durante mucho tiempo han de estar sujetos a los meriníes que, a su vez, se proclaman califas. Tal vez si Ismā‘îl hubiese reinado más tiempo, tras la batalla de la Vega y las diversas plazas conquistadas a los castellanos, el califato se habría hecho público, pero el primer emir de la segunda dinastía es asesinado en el 725/1325, y su hijo Muhammad IV es un menor de edad cuyo sometimiento a los meriníes es tal que ha de pedirles permiso para importar trigo de Casti1la ${ }^{24}$. En cambio, cuando el joven Muhammad concede el visirato a su antiguo preceptor, Abū 1-Nu'aym Riḍ̂ān ${ }^{25}$, éste recibe el título de hââyib (17 de râyab de 729/17 de mayo de 1329), título que se utilizó sobre todo en al-Andalus durante el califato omeya. No creemos que el título vaya aparejado con las funciones de tutor que Riḍ̂ān desempeñó, porque ya hemos mencionado que lo utilizan igualmente Ibn Zamrak con Muhammad V y Abū 1-Surūr Mufarrîy con Yusūf III, sino que parece indicar que estaba ligado al título de califa que se arrogan los emires de la segunda dinastía, como ya hemos mencionado, en el ámbito privado de la corte granadina y en su aparato cortesano.

Es muy significativo el caso de Yūsuf I Mu'ayyad bi-llāh, que sube al emirato tras el asesinato de su hermano Muhammad IV el 13 de $\underline{d} \bar{u} l-h i \hat{y} \hat{y} a / 25$ de agosto de 1333, siendo menor de edad con el hââyib Riḍwān desempeñando el gobierno y bajo la tutela de su abuela Fātima, hija de Muhammad II, experta en genealogías y tal vez, la que promovió la ascendencia de $\mathrm{Sa}^{\text {' }} \mathrm{d} \mathrm{b}$. 'Ubāda ${ }^{26}$ sobre los nazaríes. A Yūsuf I sus panegiristas oficiales, Ibn al-Ŷayyāb e Ibn al-Jațīb, le

${ }^{24}$ Rubiera Mata, Ibn al-Ŷyayā̄b, 49.

${ }^{25}$ Seco de Lucena, L., "El hāâyib Ridwān, la madrasa de Granada y las murallas del Albaicín", Al-Andalus, 21 (1956), 285-296.

${ }^{26}$ Rubiera Mata, M.J. J., "La princesa Fāṭima bint al-Ahmar", Medievalismo, 6 (1996), 183-189.

Al-Qanțara (AQ) XXIX 2, julio-diciembre 2008, pp. 293-305 ISSN 0211-3589 
llaman califa con cierta frecuencia, aunque nunca Jalïfat Rasūl Allāh ni Amìr al-Mu'minin.

Ibn al-Ŷayyāb en un madīh del año 740 (XXXV) habla de «Tus compañeros los califas» y en otro, sin fecha, (XLII, f. 55) también menciona la corte califal de Yūsuf I: wa-qad a lā bābi l-jalïfati Yūsuf/bābu taqābulin bi l-samāḥi wafüduh ${ }^{27}$. Es también significativo que Ibn al-Ŷayyāb escribiese un poema para un hiŷāb con la idea de colocarlo en la Dār al-Karima (creemos que es el salón del trono de Comares), lo que nos indica un aparato cortesano califal. Su texto (CLXIV) dice así:

Soy una cortina que cae sobre el Imām, que es la sombra que se extiende sobre los hombres.

Soy el velo mayor con el que guarda el secreto, secreto de generosidad.

Con mi señor Abū l-Ḥaŷȳâŷ tengo el colmo del orgullo, mi título de gloria y la paz.

Ibn al-Jatīib utiliza el término califa relacionado con Yūsuf. Así lo hace en la casida en la que celebra la construcción del palacio de Comares, en la que dice «Has devuelto al califato sus luces» ${ }^{28}$, en un poema con ocasión de la batalla del Salado (1340) ${ }^{29}$, en dos madīh sin fecha ${ }^{30}$ y en un poema que recitó en Málaga, lugar al que Yūsuf había ido para inspeccionar la flota en el año 742 (1342) ${ }^{31}$.

Pero este título seguía siendo privado, para uso restringido de la corte, porque aunque en Comares estuviese el trono de Yūsuf I con el hiŷāb califal, en las inscripciones del Salón se habla del «trono del reino» y no del «trono califal» ${ }^{32}$, porque era un lugar público, donde tenían lugar las audiencias solemnes. En cambio, Yūsuf I se convierte en califa en las inscripciones de la Torre de la Cautiva ${ }^{33}$, ese pequeño palacio camuflado en una torre y cuya sala es una versión en miniatura del Salón de Comares, en palabras de Antonio Orihuela ${ }^{34}$. En este

${ }^{27}$ Los números romanos se refieren al orden de los poemas en Rubiera Mata, M. ${ }^{\mathrm{a}}$., Ibn al-Ŷyyāb, el otro poeta de la Alhambra, Granada, 1994.

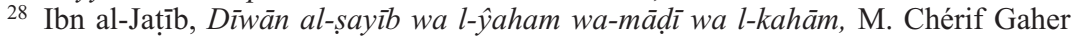
(ed.), Argel, 1973, 398-399.

29 Ibidem, 409.

30 Ibid., 422 y 428.

31 Ibid.,561.

32 García Gómez, Poemas árabes, 107-108.

33 Rubiera Mata, Ibn al-Ŷayyāb, 112-115; García Gómez, Poemas árabes, 137-143.

34 Orihuela Uzal, A., Casas y palacios nazaries. Siglos XIII-XV, Barcelona, 1996, 129-136.

Al-Qanțara (AQ) XXIX 2, julio-diciembre 2008, pp. 293-305 ISSN 0211-3589 
privadísimo palacio Yūsuf I podía ser califa sin temor a intromisiones de nadie extraño, especialmente de los meriníes que también se consideraban califas. En los paneles hay continuas alusiones a la genealogía de Yūsuf como descendiente de Sa'd b. 'Ubāda y de los Jazraŷ que, como ya hemos dicho, creemos que sirven para la legitimación del Califato Nazarí. Cabe preguntarse si este palacio en miniatura no sería levantado para dar una versión nazarí de la saqĩfa de los Anșār, ya que ésta es una especie de lugar de reunión cubierto ${ }^{35}$. En este Salón de Comares en miniatura se reuniría la familia nazarí con Yūsuf I.

La privacidad del título es tal que Ibn al-Jatîib, en los documentos que recoge en la Rayhānat al-Kuttāb ${ }^{36}$, sólo utiliza el título de califa en una carta en la que Yùsuf I autoriza el matrimonio de su hermana con un nazarí, el arráez Abū 1-Hasan 'Alī b. Nașr, mientras que en el resto de la correspondencia real Yūsuf I es sólo sultán y Amīr al-Muslimin, porque se trata de correspondencia externa. Así pues, hasta Yūsuf I el califato era una cuestión doméstica.

\section{El califa Muḥammad V}

Tras el asesinato de Yūsuf I (̌̌awwāl 755/octubre 1354) sube al trono su hijo mayor Muhammad que sólo tiene dieciséis años, y de nuevo el hââyib Riḍwān lleva los asuntos del gobierno junto a Ibn al-Jatịb. Este último, en el documento de la proclamación del nuevo emir, menciona como califa al difunto Yūsuf I ${ }^{37}$ pero no al nuevo emir. Sólo al principio de su biografía, en la Ihạta, texto redactado en el segundo reinado del monarca, le llama Jalïfat Allāh ${ }^{38}$.

Fuera de las reticencias de Ibn al-Jatị̂b de las que hablaremos luego, es cierto que Muhammad V no toma entonces el laqab califal de al-Gani bi-llāh. La razón es que aún no había ejercido la defensa efectiva del Islam, una de las notas de la legitimidad califal, como sucedió con 'Abd al-Raḥmān III ${ }^{39} \mathrm{y}$ de forma general en al-Andalus ${ }^{40}$.

35 Lecomte, G., "al-Saḳīa”, EI, Leiden, 1995, VIII, 918.

36 'Inān, M.'A. (ed.), Cairo, 1981, I, 85.

37 Ibn al-Jatīib, Rayhāna, 125.

38 Idem, al-Ihâta fì ajbār Garnāta, Cairo, 1974, II, 13.

39 Fierro, M., "Sobre la adopción del título califal por "Abd al-Rahmān III", Sharq al-Andalus, 6 (1989), 33-42.

40 Epalza, M. de, "Problemas y reflexiones sobre el califato en al-Andalus", Revista del Instituto Egipcio de Estudios Islámicos en Madrid, 21 (1981-1982), 59-73.

Al-Qanțara (AQ) XXIX 2, julio-diciembre 2008, pp. 293-305 ISSN 0211-3589 
En efecto, según Ibn Jaldūn, Muhammad V tomó el laqab tras sus victorias militares contra los cristianos en el 768/1367 41. Si echamos una mirada retrospectiva hacia los anteriores califas, Ismā'îl I y Yūsuf I reciben el título de califa tras haber conseguido también algunas victorias contra los cristianos.

Si Muhammad V se hacía acreedor del título de califa como defensor del Islam, como Anșārī debía reforzar la legitimidad dinástica, la herencia (mìrät) de sus antepasados ${ }^{42}$. Los Nazaríes ya habían encontrado la justificación de la herencia al remontar su genealogía a Sa'd b. 'Ubāda que se había proclamado califa, remontándose más allá de Nașr, que era su epónimo al principio y por lo que se llamaban nașríes, de forma que el califato no llevaría esta nisba: Ibn Simāk (m.787/1381), en el prólogo a su obra al-Zaharāt al-Mantūira ${ }^{43}$, además de llamar a Muhammad V Jalïfat Alläh, menciona que desciende del «califato al-jazraŷí».

Es evidente que los escritores de la corte de al-Ganī bi-llāh tenían que mencionar el califato que Muḥammad V ostentaba, y si ha pasado desapercibido es porque el mayor cronista de la época, Ibn al-Jatīb, no debió de aceptar nunca el califato de Muhammad V y, por tanto, no hay referencias en su extensa obra a este tema más que de pasada, posiblemente porque consideraba que Muhammad V no cumplía con sus obligaciones en defensa del Islam, como manifestó en la casida que García Gómez tituló «Epístola censoria» ${ }^{44}$. Posiblemente pensaba que el título sí lo merecían los meriníes, siempre dispuestos a reconquistar al-Andalus. No por casualidad el ideólogo del califato jazraŷî fue uno de los enemigos acérrimos de Ibn al-Jatīib. Una de las obras del qāộ̀ l-ŷamã'a Abū 1-Ḥasan al-Bunnāhī 45, Nuzhat al-bașā'ir wa-abșār ${ }^{46}$, consiste en una maqāma najliyya ${ }^{47}$ seguida de un amplio comentario histórico y filológico escrita en 1379, cuando

41 Arié, L'Espagne Musulmane, 186.

${ }^{42}$ Fierro, "Sobre la adopción", 41.

43 Edición de M.'A. Makkī, Madrid, 1404/1984, 51-54.

44 García Gómez, Foco de antigua luz, 233-239.

45 Calero Secall, M. ${ }^{a}$ I., "El proceso de Ibn al-Jațīb", Al-Qanțara, 22 (2001), 421-449.

46 Se conserva un manuscrito en la Biblioteca de El Escorial, n. ${ }^{\circ} 1653$. Fue editada parcialmente por Müller, M.J., Beiträge zur Geschichte der westlichen Araber, Munich, 1866, I, 101-106 y utilizada por Lafuente Alcántara, Inscripciones, 61-66, para establecer la genealogía de los Nazaríes.

47 Arié, R., "Notes sur la maqāma andalouse", Hespéris-Tamuda, 9 (1968), 212-213.

Al-Qanțara (AQ) XXIX 2, julio-diciembre 2008, pp. 293-305 ISSN 0211-3589 
Ibn al-Jatīb había muerto y ya nadie discutía el Califato Nazarí. El profesor Šayja consideraba que era una maqāma šu 'ūbiyya ${ }^{48}$, que defendía lo árabe (la palmera) frente a lo autóctono (la higuera), pero creemos que hay que darle otra interpretación, porque la palmera que muestra su superioridad sobre todas las plantas es la palmera plantada a la entrada de la Alhambra. Es un hecho que le produce cierto estupor a Ibn al-Jatīib ${ }^{49}$, que lo considera un tema extraño, aunque no se resiste a reproducirlo porque le menciona a él elogiosamente (es indudable que la maqāma fue escrita antes que su voluminoso comentario en el que habla de los Anșār, de Sa'd b. 'Ubāda, de la saqĩfa, del califato y de sus descendientes), lo que le permitirá comentar extensamente el episodio de la saqîfa ${ }^{50}$, incluir varios hadices sobre los Anșār ${ }^{51}$ y hacer una genealogía de los Nazaríes hasta Muhammad $\mathrm{V}^{52}$ en la que dice que "sucedió en el califato» a su padre Yùsuf I. Se trata, por tanto, de un escrito político al servicio del califato jazraŷ́ de Muhammad V, en defensa de la legitimidad de los Jazraŷ sobre el califato y la herencia de esta legitimidad en los Nazaríes ${ }^{53}$, y quién mejor que el $q \bar{a}$ ḍ̂ $l-\hat{y} a m \bar{a}^{\prime} a$ de Granada para llevar a cabo esta defensa.

\section{La ciudad califal}

Según D. Sourdel ${ }^{54}$, desde finales del siglo VII/XIII ciertos príncipes habían introducido en su titulatura la palabra jalïfa, sin utilizar en cambio amīr al-mu'minin, tal y como hacían los Nazaríes. Entre los eufemismos que utilizan para designarse califas se encuentra la denominación de su capital o residencia como Dār al-Jiläfa. Dos de los ejemplos citados por Sourdel son el turcomano Uzun Hasan (857-82/ 1453-78), que escribe al sultán otomano considerando a su nueva capital Širāz como el trono del califato, y más tarde, en la India, Akbar (1556-1605) se llama sultán y califa y considera a su capital, Delhi,

48 Šayja, Ŷ., "Min maz̄āhir šu‘ūbiyya fī l-Andalus”, Dirāsāt Andalusiyya, 4 (1990),

${ }^{49}$ Ibn al-Jațīb reproduce la maqāma en la Ihāṭa, ed. 'Inān, Cairo, 1977, IV, 95-99.

${ }^{50}$ Manuscrito de El Escorial ff. 33-34.

51 Ibidem, ff. $37 \mathrm{a}, \mathrm{b}$.

52 Ibidem, ff. 38-47.

${ }^{53}$ Fierro, "Sobre la adopción".

54 Sourdel, "Khalīfa", EI.

Al-Qanțara (AQ) XXIX 2, julio-diciembre 2008, pp. 293-305 ISSN 0211-3589 
como Dār al-Jiläfa. A los Nazaríes les faltaba este nuevo eufemismo para proclamar su califato, considerar su residencia como $D \bar{a} r$ al-Jiläfa o mejor como Kursī al-Jiläfa, y este paso lo va a dar Muhammad V, entre otras cosas porque ya en su reinado el califato deja de ser un asunto doméstico, puesto que ha conseguido independizarse plenamente del sometimiento meriní - los califas más próximoscomo indica el hecho de que reconquistase Algeciras (1369) sin ayuda de nadie ${ }^{55}$. Por esta razón Muhammad V es mencionado en las inscripciones como califa, no en un pequeño palacio escondido como la Torre de la Cautiva, sino en el Palacio de los Leones. Así se le llama en la inscripción de la Fuente de los Leones ${ }^{56}$ y se menciona el Kursī l-Jiläfa en el Mirador de Lindaraja ${ }^{57}$ que, por cierto, no creemos que se refiera exactamente al trono, situado en un mirador, sino a la «sede califal»: a todo el palacio. También se le llama califa en unas tacas, hoy desaparecidas, y que creemos se encontraban a la entrada del Salón de las Dos Hermanas ${ }^{58}$. Observamos que las referencias se encuentran en el Palacio de los Leones y no en las otras inscripciones del conjunto de Comares (fachada, Patio de los Arrayanes y sus tacas) donde aparece su nombre y que fueron compuestos por Ibn Zamrak ${ }^{59}$. Posiblemente porque estas construcciones fueron levantadas antes del año 1367 en el que hemos visto que tomó el título de al-Ganī bi-llāh. Parece que fue a partir de esta fecha cuando aparece el título de califa en las inscripciones de la Alhambra, dando una vez más la razón a la cronología apuntada por Darío Cabanelas y sus discípulos ${ }^{60}$.

Pero hay que añadir una posibilidad más. Hemos visto que los Nazaríes siguen los mismos pasos que 'Abd al-Raḥmān III en la adopción del título califal: legitimidad de los Anșār para el califato, herencia de esta legitimidad por parte de los Nazaríes y defensa del Islam ${ }^{61}$. También podría pensarse que, como apunta en un sugerente

55 Arié, L'Espagne musulmane, 117.

56 García Gómez, Poemas árabes, 113.

57 Ibidem, 125.

58 Ibn Zamrak, Dīwān, 156.

59 García Gómez, Poemas árabes, 89-99. Los poemas de las tacas en la Sala de la Barca (pp. 97-99) son de Ibn Zamrak (Dīwān, 154) y no de Ibn al-Ŷayyāb (pp. 97-99) y, por tanto, de época de Muhammad V.

${ }^{60}$ Cabanelas Rodríguez, D., "Cronología de las edificaciones de Muhammad V en la Alhambra", en Realidad y simbolo de Granada, Madrid, 1992, 189-202.

${ }^{61}$ Fierro, "Sobre la adopción".

Al-Qanțara (AQ) XXIX 2, julio-diciembre 2008, pp. 293-305 ISSN 0211-3589 
artículo Maribel Fierro ${ }^{62}$, al igual que el Califa de Córdoba Muhammad V, los Nazaríes podrían construir un palacio emblemático como lo fuera el de al-Nāșir en Madinat al-Zahrā'. Este palacio califal no sería otro que el Palacio de los Leones. Además de considerarse trono califal, en el poema del Mirador de Lindaraja, en el último verso que ha desaparecido in situ pero que se encuentra en el Dīwān de Ibn Zamrak ${ }^{63}$, se llama al Palacio de los Leones «Jardín de la Eternidad», y en las dos tacas mencionadas anteriormente de la entrada de la Sala de las Dos Hermanas, se dice que es un «Jardín del Paraíso» y «Jardín de la Eternidad», con lo que el Palacio de los Leones expresa por escrito el significado del Salón Rico de 'Abd al-Raḥmān III en Madinat al-Zahrā', que no tiene inscripciones poéticas, pero sí decoración vegetal como las construcciones de Muhammad V ${ }^{64}$. Igualmente el $\mathrm{Pa}-$ lacio de los Leones tiene esta disposición arquitectónica que evoca el Paraíso y que menciona Maribel Fierro: «(...) Hay unas habitaciones desde cuyo interior se puede ver lo que hay fuera y desde lo exterior lo que hay dentro» [relación especular entre la flora del jardín y la decoración vegetal del Salón ${ }^{65}$, rasgo con el que coincide el Palacio de los Leones y cuya relación especular se refuerza por el hecho de que en el Jardín de Lindaraja había una alberca donde se reflejaba la fachada de forma parecida al conocido efecto que hoy podemos ver en la alberca que refleja el Salón de Comares, hecho que probaremos en breve. La última concordancia, la situación elevada y resplandeciente de Madinat al-Zahrā', a semejanza del Paraíso, encuentra también su paralelo en la Alhambra. Recordemos el romance de Abenámar: «¿Qué castillos son aquéllos? ¡Altos son y relucían! La Alhambra era, señor, y la otra la mezquita, los otros los Alixares labrados a maravilla (...)», pero no creemos, en principio, que tenga una relación concreta con el Palacio/Paraíso, sino que es una tradición estética árabe que arranca de la leyenda del palacio yemení de Gumdān, donde por cierto había también leones, que arrojaban aire y no agua por sus bocas ${ }^{66}$.

\footnotetext{
299-327.

${ }^{63}$ Ibn Zamrak, Dīwān, poema n. ${ }^{\circ}$ 91, 126.

${ }^{64}$ Fierro, "Madīnat al-Zahrā",, 303-305.

65 Fierro, "Madīnat al-Zahrā"”, 311.

${ }^{66}$ Rubiera Mata, M. ${ }^{\mathrm{a}}$ J., La arquitectura en la literatura árabe, Madrid, 1988, 28-33.
}

${ }^{62}$ Fierro, M., "Madīnat al-Zahrā', el paraíso y los Fatimíes", Al-Qanțara, 25 (2004),

Al-Qanțara (AQ) XXIX 2, julio-diciembre 2008, pp. 293-305 ISSN 0211-3589 
Como hemos visto los Nazaríes adoptaron el título califal y lo justificaron con todos los argumentos posibles. Como anșāries en sus dos facetas, como defensores del Islam y como descendientes de $\mathrm{Sa}$ ' $\mathrm{d}$ b. 'Ubāda y por tanto entroncados con los califas raš̌idūn, todo lo cual no correspondía con su verdadero poder político en la Península Ibérica y respecto a los otros reinos musulmanes. Conviene recordar que, a pesar de los títulos que se arrogaban, eran conocidos simplemente por los Banū l-Ahmar. Posiblemente en lo único en que estuvieron a la altura del califato que ostentaban fue en su ciudad califal, pues Madinat al-Hamrā' sí pudo parangonarse con Madinat al-Zahrā'.

Recibido: 01/10/06

Aceptado: 07/06/07 